Canadian

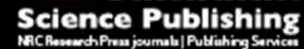

Canadian Journal of Microbiology Revue canadienne de de microbiologie

\title{
Coaggregation between Rhodococcus and Acinetobacter strains isolated from the food industry
}

\begin{tabular}{|r|l|}
\hline Journal: & Canadian Journal of Microbiology \\
\hline Manuscript ID: & cjm-2015-0210.R1 \\
\hline Danuscript Type: & Article \\
\hline Complete List of Authors: & $\begin{array}{l}\text { Møretrø, Trond; Nofima - Norwegian Institute of Food, Fisheries and } \\
\text { Aquaculture Research, } \\
\text { Sharifzadeh, Shahab; Nofima - Norwegian Institute of Food, Fisheries and } \\
\text { Aquaculture Research, } \\
\text { Langsrud, Solveig; Nofima AS, } \\
\text { Heir, Even; Nofima - Norwegian Institute of Food, Fisheries and } \\
\text { Aquaculture Research, } \\
\text { Rickard, Alex; University of Michigan, }\end{array}$ \\
\hline Keyword: & Biofilm, coaggregation, lectin, cell-cell adhesion \\
\hline
\end{tabular}

SCHOLARONE

Manuscripts 
1 Coaggregation between Rhodococcus and Acinetobacter strains isolated from

3

4 Trond Møretrø ${ }^{1^{*}}$, Shahab Sharifzadeh ${ }^{1,2}$, Solveig Langsrud ${ }^{1}$, Even Heir ${ }^{1}$ and Alexander $\mathrm{H}$.

5 Rickard $^{3}$

6

$7 \quad{ }^{1}$ Nofima, The Norwegian Institute of Food, Fishery and Aquaculture Research, Aas, Norway

$8 \quad{ }^{2}$ Norwegian University of Life Sciences, Aas, Norway

$9{ }^{3}$ The University of Michigan, School of Public Health, Department of Epidemiology, Ann Arbor, MI, 10 USA

*Correspondence

13

Trond Møretrø,

14 Nofima,

15 The Norwegian Institute of Food, Fishery and Aquaculture Research

16 P.O. Box 210

$17 \quad \mathrm{~N}-1431$ Aas

18 Norway

19

20

Email: Trond.Moretro@nofima.no

21

22 


\section{Abstract}

25 In this study coaggregation interactions between Rhodococcus and Acinetobacter strains isolated from food processing surfaces were characterized. Rhodococcus sp. MF3727 formed intra-generic coaggregates with Rhodococcus sp. MF3803 and inter-generic coaggregates with two strains of Acinetobacter calcoaceticus (MF3293, MF3627). Stronger coaggregation between Acinetobacter calcoaceticus MF3727and Rhodococcus sp. MF3293 was observed following growth in batch-culture at $30^{\circ} \mathrm{C}$ as opposed to $20^{\circ} \mathrm{C}$, after growth in Tryptic Soy broth as compared to liquid R2A medium, and between cells in exponential and early stationary phase as compared to late stationary phase. The coaggregation ability of Rhodococcus sp. MF3727 was maintained even after heat and Proteinase K treatment, suggesting the ability to coaggregate was protein independent while the coaggregation determinants of the other strains involved proteinaceous cell-surface-associated polymers. Coaggregation was stable at $\mathrm{pH}$ 5-9. The mechanisms of coaggregation among Acinetobacter and Rhodococcus strains bare similarity to that displayed by coaggregating bacteria of oral and freshwater origin, with respect to binding between proteinaceous and nonproteinaceous determinants and the effect of environmental factors on coaggregation. protect bacteria against cleaning and disinfection.

42 


\section{Introduction}

47 In natural and man-made environments, microorganisms often form multispecies biofilms,

where the constituent microorganisms interact with each other to create dynamic and responsive communities (Costerton et al. 1995; Stoodley et al. 2002). The interactivity of the cells contributes to significant phenotypic differences, in comparison to their planktonic counterparts (Hojo et al. 2009; Kolenbrander and Phucas 1984). For example, biofilm bacteria are more tolerant to environmental stress and antimicrobials than planktonic bacteria (Gilbert et al. 2002; Mah and O'Toole 2001). For biofilm development to occur, bacteria first must adhere to surfaces. These adherent bacteria then produce extracellular polymeric substances (EPS) that can enhance the integration of other bacteria into the developing biofilm. During this developmental process, different species of bacteria can also specifically recognize and adhere to each other and this is described as coaggregation (Rickard et al. 2003). Coaggregation, that was originally thought to occur only among human dental plaque bacteria, has now been described to occur between bacteria isolated from numerous environments. These environments include human oral biofilms (Kolenbrander et al. 2006), the female urogenital tract (Ekmekci et al. 2009; Reid et al. 1988), gastrointestinal tract (Schachtsiek et al. 2004; Tareb et al. 2013), freshwater systems (Rickard et al. 2002), and most recently in biofilms growing on showerheads (Vornhagen et al. 2013).

When considering coaggregation interactions, the vast majority of research has been focused on coaggregating human dental bacteria. Furthermore, human dental plaque is arguably the most studied multi-species biofilm and from nearly every cultured oral genera, representative species have been shown to coaggregate atintra-generic and/or inter-generic levels (Kolenbrander et al. 2010; Kolenbrander et al. 2006). Oral biofilms can contain up to several hundred different types of bacteria that are organized in highly spatially structured 
arrangements. Different species occupy spatially distinct regions of an oral biofilm and are

71 often associated with specific coaggregating partners. Spatial juxtaposition through

coaggregation is advantageous as this enhances metabolic and cell-cell signalling interactions (Egland et al. 2004). Studies of the mechanisms involved in coaggregation have indicated that the interactions are typically mediated by a polysaccharide-containing receptor and a proteinaceous adhesin (Rickard et al. 2003). Although, protein adhesinprotein adhesin interactions have been also indicated to mediate coaggregations (Daep et al. 2008). Beyond studies of coaggregation between bacteria isolated from the human oral cavity, bacteria from aquatic systems have received considerable attention. Not only are these environmentally distinct studies of coaggregation but these investigations have highlighted certain potential roles of coaggregation. In particular, Min and Rickard (2009) showed that coaggregation between Micrococcus and Sphingomonas enhanced biofilm formation. Furthermore, work by Simões et al. (2008) have shown that Acinetobacter calcoaceticus coaggregates with numerous freshwater species and may act as a bridging organism between non-coaggregating strains and facilitate their retention in freshwater biofilms. Furthermore, in addition to altering biofilm development and biofilm community diversity, coaggregation has been proposed to protect partner species against disinfectants different environments have indicated that coaggregation may contribute to the enhanced colonization, retention, and protection of biofilm species. In context with the study described here, all these roles of coaggregation will conceivably have important implications

91 for biofilm development in industrial food preparation environments. The food industry is dependent on good hygienic practices to produce safe food of high quality. Microorganisms present on surfaces and equipment in the production 
94

environments may contaminate food during processing. The majority of bacteria in the food production environment are non-pathogenic (Bagge-Ravn et al. 2003; Møretrø et al. 2013; Schirmer et al. 2013). These bacteria may be involved in reducing the quality of foods, but importantly, may also facilitate colonization and survival of pathogenic bacteria. As an example, Acinetobacter calcoaceticus has been shown to promote biofilm formation of the pathogenic bacterium E. coli 0157:H7 (Habimana et al. 2010). Acinetobacter spp. and Rhodococcus spp. are frequently isolated from surfaces and equipment in the food industry (Bore and Langsrud 2005; Møretrø et al. 2013; Schirmer et al. 2013). Acinetobacter sp. may play a role in spoilage of foods (Barnes and Impey 1968; Hinton et al. 2004) and both Acinetobacter sp. and Rhodococcus sp. may be opportunistic pathogens (Bell et al. 1998;

Towner 2009). Of particular interest also, Acinetobacter calcoaceticus strains isolated from aquatic systems (Simões et al. 2008) and phenol degrading granules (Adav et al. 2008) have previously been demonstrated to form coaggregates with bacteria from other genera.

In the present study we aimed to establish that coaggregation can occur between Acinetobacter and Rhodococcus isolated from food processing surfaces and, furthermore, to characterize the influence of environmental factors on coaggregation as well as the mechanisms involved in coaggregation. Of significance, our findings indicate that species belonging to these two genera have the potential to use coaggregation to recruit species into biofilms, such as those found on industrial food preparation surfaces, and this may be important for the integration and protection of pathogenic species. 
116

117

118

119

120

121

122

123

124

125

126

127

128

129

130

131

132

133

134

135

136

137

138

\section{Materials and methods}

\section{Bacterial strains}

Strains of Rhodococcus and Acinetobacter that were used in this study are shown in Table 1.

The strains Ac. calcoaceticus MF3293 and Rhodococcus sp. MF3727 were subject to an initial coaggregation study and shown to coaggregate with each other (A.H. Rickard, not published). All strains, including Ac. calcoaceticus MF3293 and Rhodococcus sp. MF3727, were isolated from surfaces of equipment/machines in the Norwegian food industry. Species designation was done by $16 \mathrm{~S}$ rDNA sequencing of $800-1450 \mathrm{bp}$, followed by BLAST sequence comparison searches (http://blast.ncbi.nlm.nih.gov/Blast.cgi).

\section{Culturing and preparation of cell suspensions for aggregation studies}

Unless otherwise stated, bacterial suspensions for aggregation measurements were prepared as follows: A single colony from Tryptone Soy Agar (TSA, Oxoid, Basingstoke, UK) was transferred to a tube with $5 \mathrm{ml}$ Tryptone Soy Broth (TSB, Oxoid). The tube was incubated overnight in a shaking incubator $(200 \mathrm{rpm})$ at $30^{\circ} \mathrm{C}$, before $500 \mu \mathrm{l}$ was transferred into an Erlenmeyer flask containing $50 \mathrm{ml}$ tempered $\left(30^{\circ} \mathrm{C}\right) \mathrm{TSB}$, and incubated at $30^{\circ} \mathrm{C}$ for $18 \mathrm{~h}$ at $200 \mathrm{rpm} .45 \mathrm{ml}$ of culture was harvested by centrifugation at $2000 \mathrm{~g}$ for $20 \mathrm{~min}$, and washed three times with $45 \mathrm{ml}$ deionized water. Then cells were re-suspended in coaggregation buffer $\left(\mathrm{CaCl}_{2}\left(10^{-4} \mathrm{~mol} \mathrm{I}^{-1}\right), \mathrm{MgCl}_{2}\left(10^{-4} \mathrm{~mol} \mathrm{I}^{-1}\right)\right.$ and $\mathrm{NaCl}\left(0.15 \mathrm{~mol} \mathrm{I}^{-1}\right)$ dissolved in $0.001 \mathrm{~mol} \mathrm{I}^{-1}$ Tris (hydroxymethyl) aminomethane, adjusted to $\mathrm{pH} 8.0$ (Kolenbrander and Phucas 1984)) to a $\mathrm{OD}_{650 \mathrm{~nm}}$ of 1.5 . The resulting suspensions were tested for coaggregation and autoaggregation. 


\section{Aggregation assays}

\section{Visual aggregation assay}

143 The degree of aggregation was determined visually by observing flocculation and

144 sedimentation of a bacterial suspension under a magnifying lamp, using the methodology

145 and ranking system of Cisar et al. (1979), with slight modifications. To evaluate whether the

146 observed aggregation was a result of coaggregation, all individual strains were also tested

147 for autoaggregation by the same procedure. Prepared suspensions ( $200 \mu \mathrm{l})$ from each of the

148 pair of strains to be tested were added into a Silica Durham tube (Borosilicate Glass 12x75

$149 \mathrm{~mm}$, Fisher brand, Waltham, MA, USA). The suspension was vortexed, rolled slowly for $10 \mathrm{~s}$

150 and then left for $30 \mathrm{~s}$ at room temperature. Then the suspensions were investigated visually

151 under a magnifying lamp immediately, and after 1 and $2 \mathrm{~h}$. If aggregation occurs, the

152 bacterial cells stick together and result in a relatively transparent suspension with high

153 sedimentation of flocs. An aggregation score rating scheme was used: Score "0" - no

154 observable flocs/coaggregates formed. Score "1" - very small flocs formed. Score "2" -

155 formation of flocs that are not sedimentary, leaving a turbid suspension. Score " 3 "-

156 generation of flocs that are sedimentary but with a suspension with some degree of

157 turbidity. Score " 4 "- generation of large flocs that sediment immediately and result in a

158 suspension that is very transparent in its upper parts.

\section{Spectrophotometric aggregation assay}

In addition to a visual assay, a quantitative optical density method was used to measure aggregation (Ekmekci et al. 2009). After preparing the suspensions, $0.5 \mathrm{ml}$ of each strain to 
163 be tested was transferred into a cuvette with total volume of $1 \mathrm{ml}$ and mixed by pipette for

$16410 \mathrm{~s}$. To determine autoaggregation, $1 \mathrm{ml}$ suspensions of individual strains were used. Then

165 the absorbance $(650 \mathrm{~nm})$ was read by spectrophotometer (Ultraspec 3000, Pharmacia

166 Biospec, Cambridge, UK) immediately and also after leaving the suspension completely still

167 for 1 and $2 \mathrm{~h}$. The coaggregation percentage (after $2 \mathrm{~h}$ ) was calculated as described

168 previously (Ekmekci et al. 2009).

\section{Effect of culturing conditions on coaggregation}

171 To test the effect of culturing conditions on coaggregation, the strains Rhodococcus sp.

172 MF3727 and Ac. calcoaceticus MF3293 were cultivated under different conditions before

173 coaggregation was tested. The tested conditions were growth in R2A or TSB medium at 20 or

$17430^{\circ} \mathrm{C}$. Cultures were harvested at exponential phase $\left(\mathrm{OD}_{600 \mathrm{~nm}}\right.$ of 0.5 (reached after $2 \mathrm{~h}$ and

$1753.5 \mathrm{~h}$ incubation for Acinetobacter calcoaceticus MF3293 and Rhodococcus sp. MF3727,

176 respectively), and after $18 \mathrm{~h}$ and $42 \mathrm{~h}$ growth. The washing and re-suspension regime was as

177 described above. This experiment and all the aggregation experiments described below were

178 performed in triplicates. In all experiments coaggregation was determined both with the

179 visual- and the spectrophotometric assay.

180

\section{Effect of washing and re-suspension solution on coaggregation}

182 Given that food processing biofilms may develop in different milieu, for example in water or 183 more ionic solutions (e.g food residues) the impact of the presence of salts/ions were tested.

184 To determine the effect of washing solution on coaggregation, suspensions of Rhodococcus 185 sp. MF3727 and Ac. calcoaceticus MF3293 were washed three times with either sterile $\mathrm{dH}_{2} \mathrm{O}$ 
or coaggregation buffer before re-suspension in coaggregation buffer and measurement of coaggregation. To study the effect of the presence of salts during the coaggregation test, coaggregation of Rhodococcus sp. MF3727 and Ac. calcoaceticus MF3293 was determined for bacterial suspensions washed with $\mathrm{dH}_{2} \mathrm{O}$ and re-suspended in coaggregation buffer, $0.85 \% \mathrm{NaCl}$ or $\mathrm{dH}_{2} \mathrm{O}$, respectively.

\section{Characterization of coaggregates}

193

194

195

\section{Effect of heat treatment}

Proteinaceous coaggregation determinants will be inactivated by heat treatment. The effect of heat treatment on coaggregation was studied. Cell suspensions $(1.5 \mathrm{ml})$ were heat-treated at $85{ }^{\circ} \mathrm{C}$ for $30 \mathrm{~min}$ (Eppendorf, Thermomixer 5436, Hamburg, Germany). The suspensions were cooled in a water bath at $20^{\circ} \mathrm{C}$ for $20 \mathrm{~min}$ and coaggregation of different pairs of heattreated and control suspensions (no heat treatment, but otherwise same treatment as heat treated suspension) were determined.

\section{Effect of enzymatic treatment}

Enzymatic treatment may destabilize cell-surface associated polymers, and can indicate the nature of the coaggregation determinants, e.g. inhibition of coaggregation by Proteinase K, indicate that the coaggregation determinant is proteinaceous. The effect of different enzymes on aggregation was tested according to previous research (Chaignon et al. 2007; Schachtsiek et al. 2004), with modifications. Cells washed three times in $\mathrm{dH}_{2} \mathrm{O}$ were resuspended to $1 \times 10^{8}$ cells $\mathrm{ml}^{-1}$ in buffer added enzymes. The following combinations of buffers and enzymes were used: Proteinase $\mathrm{K}\left(1 \mathrm{~g} \mathrm{I}^{-1}\right.$, Sigma Aldrich, Oslo, Norway) in 0.02 
210

211

212

213

214

215

216

217

218

219

220

221

222

223

224

225

226

227

228

229

230

231

232

233

mol ${ }^{-1}$ Tris $(\mathrm{pH} 7.5)+0.1 \mathrm{~mol} \mathrm{I}^{-1} \mathrm{NaCl}$, Dispersin B (40 mg $\mathrm{I}^{-1}$, Kane Biotech Inc., Winnipeg, Canada) in PBS, DNAse I (0.1 $\mathrm{gl}^{-1}$, Sigma) in $0.15 \mathrm{~mol} \mathrm{I}^{-1} \mathrm{NaCl}+0.001 \mathrm{~mol} \mathrm{I}^{-1} \mathrm{CaCl}_{2}$. The same volume of sterile de-ionized water was added to prepare control (untreated) suspensions. The suspensions were incubated in a shaker-incubator for $60 \mathrm{~min}$ at $37^{\circ} \mathrm{C}$, washed and resuspended in coaggregation buffer. Coaggregation between different pairs of enzymetreated and control suspensions was determined.

\section{Effect of sugars}

Sugars may inhibit coaggregation by competitive inhibition. The capability of different sugars (selected based on previous studies (Kolenbrander et al. 1993; Kolenbrander et al. 2006)) to reverse or inhibit the coaggregation was studied. Durham tubes or cuvettes containing a coaggregating pair was added each of the following sugars to a final concentration of 0.05 $\mathrm{mol} \mathrm{I}^{-1}$ : Lactose monohydrate (Sigma), D (+) galactose (Sigma), $\alpha$-L-fucose (Sigma), N-acetylD-galactosamine (Sigma), D (+) glucose (Merck, Oslo, Norway) and D-mannose (Sigma). Control was added sterile de-ionized water. The samples were vortexed for $10 \mathrm{~s}$ and aggregation determined.

\section{Effect of chelating agents}

The capability of different chelating agents to disperse or inhibit coaggregation was studied as described previously (Grimaudo et al. 1996; Malik et al. 2003). Durham tubes or cuvettes containing a coaggregating pair was added each of the following: EDTA (Merck $0.05 \mathrm{~mol} \mathrm{I}^{-1}$ ), EGTA (Merck, $0.05 \mathrm{~mol} \mathrm{I}^{-1}$ ) or citrate (Merck, $0.005 \mathrm{~mol} \mathrm{I}^{-1}$ ). A control sample was prepared by adding the same volume of sterile de-ionized water. The samples were vortexed for 10 seconds and coaggreation were determined. 


\section{Effect of $\mathrm{pH}$}

Fourteen tubes of cell suspensions were prepared separately for each pair of the coaggregating strains. The $\mathrm{pH}$ of each suspension was set to be from 1 to 14 (in increments of 1) by the addition of $\mathrm{NaOH}$ and $\mathrm{HCl}$. Single-species cell suspensions were incubated for 20 min at room temperature. Subsequently, the different single-species suspensions of bacteria, with same $\mathrm{pH}$, were combined and coaggregation evaluated.

\section{Scanning electron microscopy}

243 In order to visualize coaggregates, scanning electron microscopy (SEM) was performed on

244 single-species and dual-species coaggregated suspensions. The initial fixation of bacteria was 245 performed by incubation of bacterial cells (pre-grown in TSB at $30^{\circ} \mathrm{C}$ for $18 \mathrm{~h}$, and prepared 246 for aggregation assays as described above) in 2.5\% glutaraldehyde in PBS buffer (phosphate247 buffered saline). A cover slip pretreated with poly-L- lysine was placed in the cell suspension 248 for $30 \mathrm{~min}$ to allow the bacteria to attach. Loosely attached bacteria were removed by gentle 249 rinsing in $1 \mathrm{ml}$ sterile de-ionized water for a couple of seconds. The cover slip was dried in 250 steps of $5 \mathrm{~min}$ in increasing concentrations of ethanol $(70,90,96,100 \%)$. The step with $251100 \%$ ethanol was repeated three times. The sample was dried by a critical point dryer (BAL252 TEC CPD 030, BAL-TEC AG, Blazers, Germany). The dry samples were sputter-coated with (5$2537 \mathrm{~nm}$ ) gold/ palladium (Sputter Coater, Polaron SC 7640, Quorum Technologies Ltd, East 254 Sussex, UK) before examination in the microscope (Zeiss EVO-50-EP, Carl Zeiss SMT Ltd, 255 Cambridge, UK).

\section{Results}


Coaggregation of Acinetobacter calcoaceticus MF3293 and Rhodococcus sp.

259

260

\section{MF3727}

Initially, coaggregation studies focused on the pair Ac. calcoaceticus MF3293 and Rhodococcus sp. M3727 which had previously been observed to coaggregate. This pair was studied in depth to create a standardized protocol for study of coaggregation between strains of Rhodococcus sp. and Acinetobacter sp. that had been isolated from food processing surfaces. Mixing of suspensions of Ac. calcoaceticus MF3293 and Rhodococcus sp. M3727 lead to formation of coaggregates/flocs followed by sedimentation (Fig. 1), which resulted in a decrease in optical density (Fig. 2). According to the visual classification scheme, a score of 4 was observed for this coaggregation pair. No autoaggregation was observed in the visual coaggregation assays (data not shown) while a small decrease in optical density was observed for single suspensions (Fig. 2). In general there was good correlation between the visual and spectrophotometric coaggregation tests, and all major observations in this work were supported by data from both measurement methods. Consequently, for this work we chose to focus and present mainly data based on the visual coaggregation test, as this is most widely used in other publications. Scanning electron microscopy revealed that the individual suspensions of Rhodococcus sp. MF3727 and Ac. calcoaceticus MF3293 consisted of single or pairwise cells, while the mixed suspension contained large coaggregates (Fig. 3). Acinetobacter calcoaceticus MF3293 expressed clearlyvisible surface-associated appendages, and the coaggregates appeared to be interconnected by these appendages.

The impact of cultivation conditions of Rhodococcus sp. MF3727 and Ac. calcoaceticus MF3293 on coaggregation was tested. Coaggregation was lower after $42 \mathrm{~h}$ 
281 growth, especially for Rhodococcus sp. MF3727, compared to exponential and 18 h growth

282 (Fig. 4). Higher coaggregation was found for cells grown in TSB compared to R2A and cells

283 cultivated at higher temperature ( 30 vs $20^{\circ} \mathrm{C}$, data not shown). Figure 4 shows growth and

284 coaggregation of cells from different growth phases at the conditions resulting in the

285 strongest coaggregation (TSB at $30^{\circ} \mathrm{C}$ ). The same level of coaggregation was found for cells

286 washed with $\mathrm{dH}_{2} \mathrm{O}$ and coaggregation buffer. Cells that after the washing-step were re-

287 suspended in coaggregation buffer or $0.85 \% \mathrm{NaCl}$ had similar coaggregation (visual score 4),

288 while cells re-suspended in $\mathrm{dH}_{2} \mathrm{O}$ did not coaggregate (score 0 ). Based on the results

289 presented above, we selected cultivation in TSB, at $30^{\circ} \mathrm{C}$ for $18 \mathrm{~h}$, washing cells with $\mathrm{dH}_{2} \mathrm{O}$,

290 final re-suspension in coaggregation buffer and scoring of coaggregation after incubation for

$2912 \mathrm{~h}$ as standard conditions that were used for coaggregation tests for the rest of the study,

292 unless otherwise stated.

293

294 Coaggregation among Acinetobacter and Rhodococcus from the food industry

295 Coaggregation was tested between three strains of Rhodococcus sp. (including MF3727) and 296 seven strains of Acinetobacter (including MF3293, Table 1), all isolated from the food

297 industry. Coaggregation was observed for three pairs, all involving Rhodococcus sp. MF3727:

298 MF3727 + Ac. calcoaceticus MF3293 (visual score 4), MF3727 + Ac. calcoaceticus MF3627

299 (score 3) and MF3727 + Rhodococcus sp. MF3803 (score 2). No coaggregation was observed

300 for the other 42 pairs tested (score 0) (data not shown). The strain pairs showing

301 coaggregation were subjected to further studies.

302

303 Characterization of coaggregates

304 
Given that coaggregation has been documented to involve heat and protease sensitive adhesins, the effect of heat and enzymes on coaggregation were tested. Heat treatment had no effect on the ability of Rhodococcus sp. MF3727 to form coaggregates with Ac. calcoaceticus MF3293, Ac. calcoaceticus MF3627 or Rhodococcus sp. MF3803, however heat treatment of the latter three strains completely inhibited (score 0 ) their ability to coaggregate with Rhodococcus sp. MF3727 (Table 2). Using Proteinase K treatments, visual coaggregation assays showed that Proteinase K significantly decreased the coaggregation ability of Ac. calcoaceticus (MF3627 and MF3293) and Rhodococcus sp. MF3803 (Table 2). On the other hand this enzyme had no effect on the ability of Rhodococcus sp. MF3727 to coaggregate with the other strains. Dispersin B and DNase I had no effect on coaggregation

316 of any of the strains.

\section{Effect of sugars}

319 The potential for sugars to inhibit coaggregation, through competitively inhibiting adhesinreceptor interactions, was evaluated. $\mathrm{N}$-acetylgalactoseamine led to a reduction of coaggregation between Rhodococcus sp. MF3727 and Ac. calcoaceticus MF3627 from a visual score of 3 to 2, but had only minor adverse effects on coaggregation of the two other coaggregating pairs (data not shown). Lactose monohydrate inhibited coaggregation between Rhodococcus sp. MF3727 and Ac. calcoaceticus MF3293 and between Rhodococcus sp. MF3727 and Rhodococcus sp. MF3803 by $17 \%$ and $15 \%$ according to the spectrophotometric assay, respectively, while no effects were observed in the visual assay. 
328 less than $10 \%$ in the spectrophotometric assay, while no effects were observed with the

329 visual assay.

330

331 Effect of chelating agents

332 The dependency of cations on coaggregation was investigated by adding chelating agents to

333 coaggregating suspensions. It was observed that citrate slightly limited the coaggregation

334 ability (reduction from 4 to 3 ) of the coaggregating pair Rhodococcus sp. MF3727 + Ac.

335 calcoaceticus MF3293. No effects on coaggregation were observed with the visual assay for

336 EDTA and EGTA, while a 4-18\% inhibition of coaggregation was observed in the

337 spectrophotometric test.

338

339 Effect of $\mathrm{pH}$

340 The effect of $\mathrm{pH}$ on coaggregation was evaluated by combining suspensions of coaggregating

341 cells with similar $\mathrm{pH}$ for the range $\mathrm{pH}$ 1-14. The results showed that coaggregation was

342 stable at $\mathrm{pH}$ 5-9 for all three pairs of bacteria tested. For two of the pairs, coaggregation

343 decreased at higher $\mathrm{pH}$, while for the pair Rhodococcus sp. MF3727 + Rhodococcus sp.

344 MF3803, coaggregation increased at low pH (Fig. 5). It should be noted that cells tested

345 outside a pH-range of 3-11 were observed to undergo lysis and no coaggregation occurred.

346

347 


\section{Discussion}

350 In this work, strain-specific coaggregation was observed in vitro between Rhodococcus and

351

352

353

Acinetobacter isolates from food production environments. In order to identify

coaggregation interactions between strains from these genera we optimized the sensitivity for testing coaggregation using a model pair of strains isolated from food processing surfaces and explored the parameters that influenced the strength of expression of coaggregation.

This yielded insight, concerning conditions that may allow food processing bacteria to coaggregate, which allowed additional strains to be tested. Two of these additional strains, that were isolated from different food processing surfaces, were also shown to coaggregate suggesting that coaggregation may be common to biofilms containing Rhodococcus and Acinetobacter. For Acinetobacter, coaggregation seemed to differ between species as both strains of Ac. calcoaceticus coaggregated, while coaggregation was not observed for strains from other species of Acinetobacter. Although there have been many studies of multispecies biofilms involving bacteria from the food industry (for a review, see Srey et al. 2013), to our knowledge this is the first time coaggregation among bacteria from food industry has been reported. Also, we are not aware of reports describing coaggregation between Acinetobacter sp. and Rhodococcus sp. from other sources, but the ability of Acinetobacter to coaggregate with Oligotropha carboxidovorans, Methylobacterium sp. and Staphylococcus sp. has previously been reported (Malik et al. 2003; Simões et al. 2008).

Our results from heat and Proteinase $\mathrm{K}$ treatments of bacterial suspensions indicated that the coaggregation polymers expressed by Rhodococcus sp. MF3803 and Ac. calcoaceticus MF3293 and MF3627 were proteinaceous, while the coaggregation polymers 

of Rhodococcus sp. MF3727 were non-proteinaceous. The protein structures involved in coaggregation of Ac. calcoaceticus MF3293 might be part of the appendages or fimbriae observed by scanning electron microscopy (Fig. 3). It has previously been indicated that Acinetobacter has proteinaceous cell-surface expressed coaggregation polymers (Malik et al. 2003; Simões et al. 2008). Reports indicate that coaggregation between bacteria isolated

376 from the human oral cavity and between bacteria isolated from drinking water is mediated 377 by cell-surface expressed adhesins (proteinacious lectin-like polymers) and cell-surface expressed receptors (polysaccharides containing polymers)(Kolenbrander 1988; Rickard et al. 2004). Based on this it is likely that the coaggregation determinant of Rhodococcus sp. MF3727 is a polysaccharide. A schematic overview of the proposed adhesin-receptor based coaggregation between Rhodococcus and Acinetobacter is shown in Figure 6. Previous studies of coaggregation between oral and between freshwater bacteria, as well as between bacteria from a other environments, has shown that certain simple sugars are able to competitively inhibit adhesin-receptor coaggregation interactions (Kolenbrander 1988; Kolenbrander et al. 1993). In this study, however only limited inhibition was observed by adding selected sugars to the coaggregating suspensions. Even if $\mathrm{N}$-acetyl-D-galactosamine and lactose exerted a slightly inhibitory effect on some coaggregation pairs involving Rhodococcus sp. MF3727, other coaggregation pairs involving Rhodococcus sp. MF3727 were unaffected. Thus the sugar involved in the coaggregation binding was not identified. However, it cannot be ruled out that the coaggregation associated polymer was a polysaccharide, because sugars other than those tested in the present study may inhibit the interaction. Other sugars could be tested in future studies, but we did test the activity of dispersin B. While dispersin B did not have any inhibitory effect either, the absence of a discernable inhibitory effect of adding dispersin B to coaggregates, does not necessarily 
exclude the possibility of a polysaccharide coaggregation polymer. This is because dispersin

B cleavage is specific for $\beta$ 1,6 N-acetylglucosamine (Kaplan et al. 2004) and will not be active against all polysaccharides. As heat treated Rhodococcus sp. MF3727 could form coaggregates, this shows that bacteria may coaggregate even if they are inactivated. This is because the cell wall with its cell-surface expressed polysaccharides may still remain relatively unaffected by heat treatment. However, it is possible that bacteria may disintegrate during other types of control measures, e.g. disinfection, so dead cells may not be able to coaggregate on all occasions.

Coaggregation was relatively stable within a $\mathrm{pH}$ range relevant for food and food production. The effects on coaggregation observed at extreme acidity/alkalinity can be explained by alterations in the charge of proteins and carbohydrates that may affect electrostatic interactions important for coaggregation (Min et al. 2010). The strains Rhodococcus sp. MF3727 and Ac. calcoaceticus MF3293 showed strongest coaggregation when suspended in coaggregation buffer or $0.85 \% \mathrm{NaCl}$, while no coaggregation occurred in $\mathrm{dH}_{2} \mathrm{O}$. This indicates that the presence of ions is important for the coaggregation binding. However it is not clear whether anions or cations are most important since the chelators citrate, EDTA and EGTA only had limited effect on coaggregation. Ionic strength of the surroundings can affect electrostatic interactions between the surface-expressed appendages of the coaggregation partners (Bos et al. 1999). Bacteria in the food industry are likely to be exposed to ions from e.g. food residues, salts added to foods, tap water and cleaning agents and disinfectants. Coaggregation between Rhodococcus sp. MF3727 and Ac. calcoaceticus MF3293 was stronger under conditions with high growth rate (TSB vs R2A, 30 vs $20^{\circ} \mathrm{C}$, exponentially/early stationary vs late stationary growth). It is possible that the cell-surface-associated polymers 
419 that mediate coaggregation are more highly expressed under conditions with high growth.

420 Changes in growth temperature may affect the expression of structures on cell surface that

421 mediate coaggregation or adhesion (Amano et al. 2001; Briandet et al. 1999). Also studies by

422 other researchers have indicated that stronger coaggregation interactions occur between

423 bacteria grown at higher temperatures (Jenkinson et al. 1990; Joe et al. 2009) and in more

424 nutritious growth media (Burdman et al. 1998; Mclntire et al. 1978). Coaggregation was

425 observed under conditions relevant for the food industry. Food residues will be present on

426 many surfaces and will provide nutrients for bacterial growth. The temperature will vary

427 between types of production and within a processing plant but temperatures around 20-30

$428{ }^{\circ} \mathrm{C}$ are not uncommon, e.g. in areas where food are heated and during cleaning and

429 disinfection.

430 The increased prevalence of antibiotic resistant Acinetobacter in foods is of concern

431 (Guerra et al. 2014). Although Acinetobacter is not frequently identified as the cause of

432 microbial spoilage, it has been associated with spoilage of meat, seafood and poultry stored

433 at cooling temperatures (Barnes and Impey 1968; Hinton et al. 2004). Rhodococcus equi

434 causes mainly lung associated infections in immunocompromised individuals, but also other

435 species of Rhodococcus, such as R. erythropolis have been reported to cause infections (Bell

436 et al. 1998). Acinetobacter and Rhodococcus species are commonly found in food processing

437 plants, and have the ability to form biofilms (Aaku et al. 2004; Bore and Langsrud 2005;

438 Lewis et al. 1989; Møretrø et al. 2013; Schirmer et al. 2013). Acinetobacter calcoaceticus has

439 been shown to promote biofilm formation by the pathogenic bacteria Escherichia coli

440 O157:H7, however the mechanisms involved were not investigated (Habimana et al. 2010).

441 Also the food borne pathogenic bacterium Listeria monocytogenes is a relatively poor biofilm

442 former (Møretrø et al. 2013), which adhesion and biofilm formation may be induced in 
443 multispecies biofilms (Bremer et al. 2001; Hassan et al. 2004). Given the available literature

444 it is likely that species of Acinetobacter and Rhodococcus may promote biofilm recruitment

445 of each other and other species including pathogenic bacteria and this could be in part due

446 to coaggregation interactions. For other environments coaggregation has been shown to

447 occur between bacteria co-isolated from the same biofilm, leading to the assumption that

448 the ability to coaggregate is advantageous for growth and survival in such environments

449 (Kolenbrander 1988; Rickard et al. 2003). Also it has been shown that coaggregation has a

450 positive effect on biofilm formation in multispecies biofilm (Min and Rickard 2009).

451 Bacteria adhere to each other, to equipment, and to food. The biofilms that form are

452 difficult to remove, act as a source for spreading of microorganisms to uncolonized surfaces

453 and act as a shelter against cleaning and disinfection (Bridier et al. 2015; Srey et al. 2013). A

454 better understanding of cooperation and interactions in biofilms, such as coaggregation,

455 may facilitate the development of improved and targeted strategies for control of biofilms.

456 Enzymatic treatment can degrade the biofilm matrix (Srey et al. 2013) and can also be a

457 strategy for breaking up coaggregates. In particular, while the information generated from

458 this early study is useful and will help direct future studies of coaggregation between

459 bacterial isolates from the food industry, more research is necessary to reveal how often and

460 under what conditions coaggregation occurs among other frequently isolated bacterial

461 species from the food industry. Ultimately, a key question, for which this work sets the

462 rationale to investigate, is whether bacterial coaggregation influences the growth, retention,

463 and survival of pathogenic species in food processing facilities.

464

465

466 Acknowledgements 
467 The research was funded by the Norwegian fund for Research Levy on Agricultural products.

468 The authors wish to thank Elin Ørmen, Microscopy lab, Norwegian University of Life Sciences 469 for performing the Scanning electron microscopy and Kjell Merok, Nofima, for the photos of 470 coaggregation.

471

472

473 


\section{References}

475

476

477

478

479

480

481

482

483

484

485

486

487

488

489

490

491

492

493

494

495

496

Aaku, E.N., Collison, E.K., Gashe, B.A., and Mpuchane, S. 2004. Microbiological quality of milk

from two processing plants in Gaborone Botswana. Food Control 15(3): 181-186. doi:

10.1016/s0956-7135(03)00031-8.

Adav, S.S., Lee, D.-J., and Lai, J.-Y. 2008. Intergeneric coaggregation of strains isolated from phenol-degrading aerobic granules. Appl. Microbiol. Biotechnol. 79(4): 657-661. doi:

10.1007/s00253-008-1456-8.

Amano, A., Premaraj, T., Kuboniwa, M., Nakagawa, I., Shizukuishi, S., Morisaki, I., and

Hamada, S. 2001. Altered antigenicity in periodontitis patients and decreased adhesion of

Porphyromonas gingivalis by environmental temperature stress. Oral Microbiol. Immunol.

16(2): 124-128. doi: 10.1034/j.1399-302x.2001.016002124.x.

Bagge-Ravn, D., Ng, Y., Hjelm, M., Christiansen, J.N., Johansen, C., and Gram, L. 2003. The microbial ecology of processing equipment in different fish industries - analysis of the microflora during processing and following cleaning and disinfection. Int. J. Food Microbiol. 87(3): 239-250.

Barnes, E.M., and Impey, C.S. 1968. Psychrophilic spoilage bacteria of poultry. J. Appl.

Bacteriol. 31(1): 97-\&. doi: 10.1111/j.1365-2672.1968.tb00345.x.

Bell, K.S., Philp, J.C., Aw, D.W.J., and Christofi, N. 1998. A review - The genus Rhodococcus. J. Appl. Microbiol. 85(2): 195-210.

Bore, E., and Langsrud, S. 2005. Characterization of micro-organisms isolated from dairy industry after cleaning and fogging disinfection with alkyl amine and peracetic acid. J. Appl.

Microbiol. 98(1): 96-105. doi: 10.1111/j.1365-2672.2004.02436.x. 
497

498

499

500

501

502

503

504

505

506

507

508

509

510

511

512

513

514

515

516

517

518

519

520

Bos, R., van der Mei, H.C., and Busscher, H.J. 1999. Physico-chemistry of initial microbial adhesive interactions - its mechanisms and methods for study. FEMS Microbiol. Rev. 23(2):

179-230. doi: 10.1016/s0168-6445(99)00004-2.

Bremer, P.J., Monk, I., and Osborne, C.M. 2001. Survival of Listeria monocytogenes attached to stainless steel surfaces in the presence or absence of Flavobacterium spp.. J. Food Prot.

64(9): 1369-1376.

Briandet, R., Meylheuc, T., Maher, C., and Bellon-Fontaine, M.N. 1999. Listeria

monocytogenes Scott A: Cell surface charge, hydrophobicity, and electron donor and

acceptor characteristics under different environmental growth conditions. Appl. Environ.

Microbiol. 65(12): 5328-5333.

Bridier, A., Sanchez-Vizuete, P., Guilbaud, M., Piard, J.C., Naitali, M., and Briandet, R. 2015.

Biofilm-associated persistence of food-borne pathogens. Food Microbiol. 45: 167-178. doi:

10.1016/j.fm.2014.04.015.

Burdman, S., Jurkevitch, E., Schwartsburd, B., Hampel, M., and Okon, Y. 1998. Aggregation in Azospirillum brasilense: effects of chemical and physical factors and involvement of

extracellular components. Microbiology-Uk 144: 1989-1999.

Chaignon, P., Sadovskaya, I., Ragunah, C., Ramasubbu, N., Kaplan, J.B., and Jabbouri, S. 2007. Susceptibility of staphylococcal biofilms to enzymatic treatments depends on their chemical composition. Appl. Microbiol. Biotechnol. 75(1): 125-132. doi: 10.1007/s00253-006-0790-y.

Cisar, J.O., Kolenbrander, P.E., and McIntire, F.C. 1979. Specificity of coaggregation reaction between human oral streptococci and strains of Actinomyces viscosus or Actinomyces naeslundii Infect. Immun. 24(3): 742-752.

Costerton, J.W., Lewandowski, Z., Caldwell, D.E., Korber, D.R., and Lappin-Scott, H.M. 1995. Microbial biofilms. Annu. Rev. Microbiol. 49: 711-742. 
Daep, C.A., Lamont, R.J., and Demuth, D.R. 2008. Interaction of Porphyromonas gingivalis with oral streptococci requires a motif that resembles the eukaryotic nuclear receptor box protein-protein interaction domain. Infect. Immun. 76(7): 3273-3280. doi:

10.1128/iai.00366-08.

Egland, P.G., Palmer, R.J., and Kolenbrander, P.E. 2004. Interspecies communication in Streptococcus gordonii-Veillonella atypica biofilms: Signaling in flow conditions requires juxtaposition. Proc. Natl. Acad. Sci. USA 101(48): 16917-16922. doi:

10.1073/pnas.0407457101.

Ekmekci, H., Aslim, B., and Ozturk, S. 2009. Characterization of vaginal lactobacilli coaggregation ability with Escherichia coli. Microbiol. Immunol. 53(2): 59-65. doi: 10.1111/j.1348-0421.2009.00115.x.

Gilbert, P., Maira-Litran, T., McBain, A.J., Rickard, A.H., and Whyte, F.W. 2002. The physiology and collective recalcitrance of microbial biofilm communities. Adv. Microb.

Physiol. 46: 202-256.

Grimaudo, N.J., Nesbitt, W.E., and Clark, W.B. 1996. Coaggregation of Candida albicans with oral Actinomyces species. Oral Microbiol. Immunol. 11(1): 59-61. doi: 10.1111/j.1399-

302X.1996.tb00337.x.

Guerra, B., Fischer, J., and Helmuth, R. 2014. An emerging public health problem: Acquired carbapenemase-producing microorganisms are present in food-producing animals, their environment, companion animals and wild birds. Vet. Microbiol. 171(3-4): 290-297. doi: 10.1016/j.vetmic.2014.02.001.

Habimana, O., Heir, E., Langsrud, S., Asli, A.W., and Møretrø, T. 2010. Enhanced surface colonization by Escherichia coli 0157:H7 in biofilms formed by an Acinetobacter 
calcoaceticus Isolate from meat-processing environments. Appl. Environ. Microbiol. 76(13):

545

546

547

548

549

550

551

552

553

554

555

556

557

558

559

560

561

562

563

564

565

566

567 4557-4559. doi: 10.1128/aem.02707-09.

Hassan, A.N., Birt, D.M., and Frank, J F. 2004. Behavior of Listeria monocytogenes in a Pseudomonas putida biofilm on a condensate-forming surface. J. Food Prot. 67(2): 322-327.

Hinton, A., Cason, J.A., and Ingram, K.D. 2004. Tracking spoilage bacteria in commercial poultry processing and refrigerated storage of poultry carcasses. Int. J. Food Microbiol.

91(2): 155-165. doi: 10.1016/s0168-1605(03)00377-5.

Hojo, K., Nagaoka, S., Ohshima, T., and Maeda, N. 2009. Bacterial interactions in dental biofilm development. J. Dent. Res. 88(11): 982-990. doi: 10.1177/0022034509346811.

Jenkinson, H.F., Lala, H.C., and Shepherd, M.G. 1990. Coaggregation of Streptococcus sanguis and other streptococci with Candida albicans. Infect. Immun. 58(5): 1429-1436.

Joe, M.M., Jaleel, C.A., Sivakumar, P.K., Zhao, C.-X., and Karthikeyan, B. 2009. Co-aggregation in Azospirillum brasilensense MTCC-125 with other PGPR strains: Effect of physical and

chemical factors and stress endurance ability. J. Taiwan Inst. Chem. Eng. 40(5): 491-499. doi: 10.1016/j.jtice.2009.02.006.

Kaplan, J.B., Velliyagounder, K., Ragunath, C., Rohde, H., Mack, D., Knobloch, J.K.M., and Ramasubbu, N. 2004. Genes involved in the synthesis and degradation of matrix polysaccharide in Actinobacillus actinomycetemcomitans and Actinobacillus pleuropneumoniae biofilms. J. Bacteriol. 186(24): 8213-8220. doi: 10.1128/jb.186.24.82138220.2004.

Kolenbrander, P.E. 1988. Intergeneric coaggregation among human oral bacteria and ecology of dental plaque. Annu. Rev. Microbiol. 42: 627-656.

Kolenbrander, P.E., Ganeshkumar, N., Cassels, F.J., and Hughes, C.V. 1993. Coaggregation specific adherence among human oral plaque bacteria. FASEB J. 7(5): 406-413. 
568

569

570

571

572

573

574

575

576

577

578

579

580

581

582

583

584

585

586

587

588988.

589 Min, K.R., and Rickard, A.H. 2009. Coaggregation by the freshwater bacterium Sphingomonas

590 natatoria alters dual-species biofilm formation. Appl. Environ. Microbiol. 75(12): 3987-3997. 591 doi: 10.1128/aem.02843-08.

Kolenbrander, P.E., Palmer, R.J., Jr., Periasamy, S., and Jakubovics, N.S. 2010. Oral

multispecies biofilm development and the key role of cell-cell distance. Nat. Rev. Microbiol.

8(7): 471-480. doi: $10.1038 /$ nrmicro2381.

Kolenbrander, P.E., Palmer, R.J., Rickard, A.H., Jakubovics, N.S., Chalmers, N.I., and Diaz, P.I. 2006. Bacterial interactions and successions during plaque development. Periodontol. 2000

42: 47-79. doi: 10.1111/j.1600-0757.2006.00187.x.

Kolenbrander, P.E., and Phucas, C.S. 1984. Effect of saliva on coaggregation of oral

Actinomyces and Streptococcus species. Infect. Immun. 44(2): 228-233.

Langsrud, S., Seifert, L., and Møretr $\varnothing$, T. 2006. Characterization of the microbial flora in

disinfecting footbaths with hypochlorite. J. Food. Protec. 69(9): 2193-2198.

Lewis, S.J., Gilmour, A., and Johnston, D.E. 1989. Factors influencing the detachment of a polymer-associated Acinetobacter sp from stainless-steel. Int. J. Food Microbiol. 8(2): 155-

164. doi: 10.1016/0168-1605(89)90070-6.

Mah, T.F.C., and O'Toole, G.A. 2001. Mechanisms of biofilm resistance to antimicrobial agents. Trends Microbiol. 9(1): 34-39. doi: 10.1016/s0966-842x(00)01913-2.

Malik, A., Sakamoto, M., Ono, T., and Kakii, K. 2003. Coaggregation between Acinetobacter johnsonii S35 and Microbacterium esteraromaticum strains isolated from sewage activated sludge. J. Biosci. Bioeng. 96(1): 10-15. doi: 10.1016/s1389-1723(03)90090-9.

McIntire, F.C., Vatter, A.E., Baros, J., and Arnold, J. 1978. Mechanism of co-aggregation

between Actinomyces viscosus t14v and Streptococcus sanguis 34. Infect. Immun. 21(3): 978-

natatoria alters dual-species biofilm formation. Appl. Environ. Microbiol. 75(12): $3987-3997$. 
592 593 594 595 596 597

600

601

602

603

604

605

606

607

608

609

610

611

612

613

614 615

Min, K.R., Zimmer, M.N., and Rickard, A.H. 2010. Physicochemical parameters influencing coaggregation between the freshwater bacteria Sphingomonas natatoria 2.1 and

Micrococcus luteus 2.13. Biofouling 26(8): 931-940. doi: 10.1080/08927014.2010.531128.

Møretrø, T., Langsrud, S., and Heir, E. 2013. Bacteria on meat abattoir meat production process surfaces after sanitation: Characterisation of survival properties of Listeria monocytogenes and the commensal bacterial flora. Adv. Microbiol. 3: 255-264.

Reid, G., McGroarty, J.A., Angotti, R., and Cook, R.L. 1988. Lactobacillus inhibitor production against Escherichia coli and coaggregation ability with uropathogens. Can. J. Microbiol. 34(3): 344-351.

Rickard, A.H., Gilbert, P., and Handley, P.S. 2004. Influence of growth environment on coaggregation between freshwater biofilm bacteria. J. Appl. Microbiol. 96(6): 1367-1373. doi: 10.1111/j.1365-2672.2004.02297.x.

Rickard, A.H., Gilbert, P., High, N.J., Kolenbrander, P.E., and Handley, P.S. 2003. Bacterial coaggregation: an integral process in the development of multi-species biofilms. Trends Microbiol. 11(2): 94-100. doi: 10.1016/s0966-842x(02)00034-3.

Rickard, A.H., Leach, S.A., Hall, L.S., Buswell, C.M., High, N.J., and Handley, P.S. 2002. Phylogenetic relationships and coaggregation ability of freshwater biofilm bacteria. Appl.

Environ. Microbiol. 68(7): 3644-3650. doi: 10.1128/aem.68.7.3644-3650.2002.

Schachtsiek, M., Hammes, W.P., and Hertel, C. 2004. Characterization of Lactobacillus coryniformis DSM 20001(T) surface protein Cpf mediating coaggregation with and aggregation among pathogens. Appl. Environ. Microbiol. 70(12): 7078-7085. doi: 10.1128/aem.70.12.7078-7085.2004.

Schirmer, B.C.T., Heir, E., Møretrø, T., Skaar, I., and Langsrud, S. 2013. Microbial background flora in small-scale cheese production facilities does not inhibit growth and surface 
616 attachment of Listeria monocytogenes. J. Dairy Sci. 96(10): 6161-6171. doi:

$617 \quad 10.3168 / j d s .2012-6395$.

618 Simões, L.C., Simões, M., and Vieira, M.J. 2008. Intergeneric coaggregation among drinking

619 water bacteria: Evidence of a role for Acinetobacter calcoaceticus as a bridging bacterium.

620 Appl. Environ. Microbiol. 74(4): 1259-1263. doi: 10.1128/aem.01747-07.

621 Srey, S., Jahid, I.K., and Ha, S.-D. 2013. Biofilm formation in food industries: A food safety

622 concern. Food Control 31(2): 572-585. doi: 10.1016/j.foodcont.2012.12.001.

623 Stoodley, P., Sauer, K., Davies, D.G., and Costerton, J.W. 2002. Biofilms as complex

624 differentiated communities. Annu. Rev. Microbiol. 56: 187-209. doi:

625 10.1146/annurev.micro.56.012302.160705.

626 Tareb, R., Bernardeau, M., Gueguen, M., and Vernoux, J.-P. 2013. In vitro characterization of 627 aggregation and adhesion properties of viable and heat-killed forms of two probiotic

628 Lactobacillus strains and interaction with foodborne zoonotic bacteria, especially

629 Campylobacter jejuni. J. Med. Microbiol. 62: 637-649. doi: 10.1099/jmm.0.049965-0.

630 Towner, K.J. 2009. Acinetobacter: an old friend, but a new enemy. J. Hosp. Infect. 73(4): 355-

631 363. doi: 10.1016/j.jhin.2009.03.032.

632 Vornhagen, J., Stevens, M., McCormick, D.W., Dowd, S.E., Eisenberg, J.N.S., Boles, B.R., and

633 Rickard, A.H. 2013. Coaggregation occurs amongst bacteria within and between biofilms in

634 domestic showerheads. Biofouling 29(1): 53-68. doi: 10.1080/08927014.2012.744395.

635

636

637 
638

639 
640 Table 1. Bacterial strains of Acinetobacter and Rhodococcus used in this study

\begin{tabular}{|c|c|c|c|c|}
\hline $\begin{array}{l}\text { Bacterial } \\
\text { genera }\end{array}$ & Species designation (\% identity) $^{\dagger}$ & Strain number* & Origin & Reference \\
\hline Rhodococcus & erythropolis/ qingshengii (100) & 3727 & Drain, small scale cheese producer & $\begin{array}{c}\text { (Schirmer et al. } \\
\text { 2013) }\end{array}$ \\
\hline Rhodococcus & erythropolis/ qingshengii (100) & 3803 & Floor, small scale cheese producer & $\begin{array}{c}\text { (Schirmer et al. } \\
\text { 2013) }\end{array}$ \\
\hline Rhodococcus & erythropolis/ qingshengii (100) & 4633 & $\begin{array}{c}\text { Slicing machine, meat processing } \\
\text { plant }\end{array}$ & $\begin{array}{l}\text { T. Møretrø, not } \\
\text { published }\end{array}$ \\
\hline Acinetobacter & calcoaceticus (100) & 3293 & $\begin{array}{l}\text { Disinfecting footbath with } \\
\text { hypochlorite, dairy }\end{array}$ & $\begin{array}{l}\text { (Langsrud et al. } \\
\text { 2006) }\end{array}$ \\
\hline Acinetobacter & calcoaceticus (99) & 3627 & $\begin{array}{c}\text { Platform evisceration, meat } \\
\text { slaughterhouse }\end{array}$ & $\begin{array}{c}\text { (Møretrø et al. } \\
\text { 2013) }\end{array}$ \\
\hline Acinetobacter & johnsonii (99) & 4091 & $\begin{array}{l}\text { Conveyor belt, salmon processing } \\
\text { plant }\end{array}$ & $\begin{array}{l}\text { E. Heir, not } \\
\text { published }\end{array}$ \\
\hline Acinetobacter & johnsonii (99) & 4112 & $\begin{array}{l}\text { Filet machine, salmon processing } \\
\text { plant }\end{array}$ & $\begin{array}{l}\text { E. Heir, not } \\
\text { published }\end{array}$ \\
\hline Acinetobacter & guilloniae (99) & 4117 & $\begin{array}{l}\text { Conveyor belt, salmon processing } \\
\text { plant }\end{array}$ & $\begin{array}{l}\text { E. Heir, not } \\
\text { published }\end{array}$ \\
\hline Acinetobacter & johnsonii (99) & 4130 & Conveyor belt, salmon processing & E. Heir, not \\
\hline
\end{tabular}




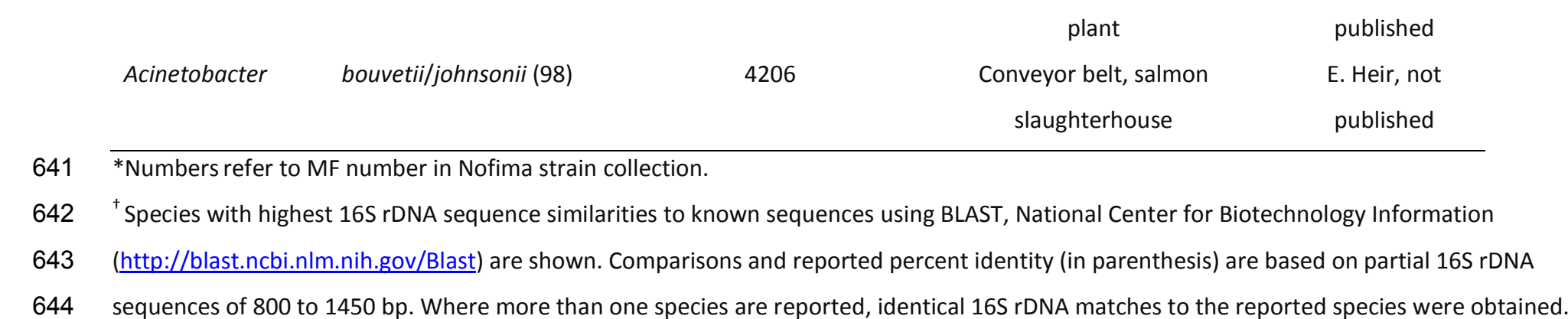


645 Table 2. Coaggregation (visual score) of pairs of Rhodococcus sp. MF3727 and

646 Acinetobacter calcoaceticus MF3293, Ac. calcoaceticus MF3627 or Rhodococcus sp.

647 MF3803 pretreated with heat or Proteinase K or untreated (control)

\begin{tabular}{|c|c|c|c|c|c|c|c|c|c|}
\hline \multirow[b]{2}{*}{ MF3727 } & \multicolumn{3}{|c|}{ MF3293 } & \multicolumn{3}{|c|}{ MF3627 } & \multicolumn{3}{|c|}{ MF3803 } \\
\hline & Control & Heat* & ProtK $^{+}$ & Control & Heat & ProtK & Control & Heat & ProtK \\
\hline Control & $4^{\ddagger}$ & 0 & 1 & 3 & 0 & 1 & 2 & 0 & 0 \\
\hline Heat & 4 & 0 & $N T^{\S}$ & 3 & 0 & NT & 2 & 0 & NT \\
\hline ProtK & 4 & NT & 1 & 3 & NT & 1 & 2 & NT & 0 \\
\hline \multicolumn{10}{|c|}{ 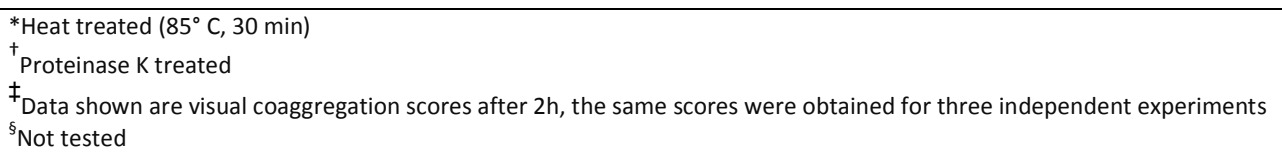 } \\
\hline
\end{tabular}




\section{Figure captions:}

658

659

660

661

662

663

664

665

666

667

668

669

670

671

672

673

674

675

676

677

678

679 Figure 5. Coaggregation at different pH of of Rhodococcus sp. MF3727 combined in pairs 680

Figure 1. Coaggregation between Rhodococcus sp. MF3727 and Acinetobacter calcoaceticus MF3293. The pictures show tubes with coaggregate formation and sedimentation A: immediately after mixing the strains. B: after $10 \mathrm{~min} C$ : after $30 \mathrm{~min}$. D: after $2 \mathrm{~h}$.

Figure 2. Decreased optical density after incubation of individual and mixed suspensions of Rhodococcus sp. MF3727 and Acinetobacter calcoaceticus MF3293. Data represent means and standard deviations from three independent replicates.

Figure 3. Scanning electron microscopy of A: individual suspension of Rhodococcus sp. MF3727; B: individual suspension of Acinetobacter calcoaceticus MF3293; C-F. Mixed suspension of MF3727 and MF3293. The arrows refer to appendages on the cell surfaces. AC 10,000 X magnification, D 20,000 X, E 60,000 X, E 40,000 X.

Figure 4. Growth (a) and coaggregation (b) of Rhodococcus sp. MF3727 and Acinetobacter calcoaceticus MF3293 in TSB medium at $30^{\circ} \mathrm{C}$. Bacteria were harvested at three time points: A; Exponential growth $\mathrm{OD}_{600 \mathrm{~nm}}=0.5$ (reached after $2 \mathrm{~h}$ and $3.5 \mathrm{~h}$ incubation for $\mathrm{MF} 3293$ and MF3727, respectively), B: 18h, C: $42 \mathrm{~h}$. Combinations of cells from various growth phases (A, $B, C)$ were tested for coaggregation. Data presented are based on the visual coaggregation score. The same scores were obtained in three independent experiments.

with Acinetobacter calcoaceticus MF3293 (घ), Acinetobacter calcoaceticus MF3627 ( $\square$ ) or 
681 Rhodococcus sp. MF3803 (A), respectively. Data presented are visual coaggregation scores.

682 The same scores were obtained in three independent experiments.

683

684 Figure 6. Schematic presentation of the proposed receptor-adhesin mediated coaggregation

685 between Rhodococcus spp. and Acinetobacter spp. Three of the strains have proteinaceous

686 adhesins (cup-shaped structures) that interact with the receptors (squares) of Rhodococcus

687 sp. MF 3727, leading to the formation of coaggregates, while the other three strains are

688 examples of strains that do not have adhesins (cup-shaped structures) interacting with the

689 receptors of Rhodococcus sp. MF3727, thus no coaggregation can occur. Rhodococcus strains

690 are shown in red and Acinetobacter strains are blue. Cell sizes and cell shapes are not to

691 scale and approximate. 
Fig.1.
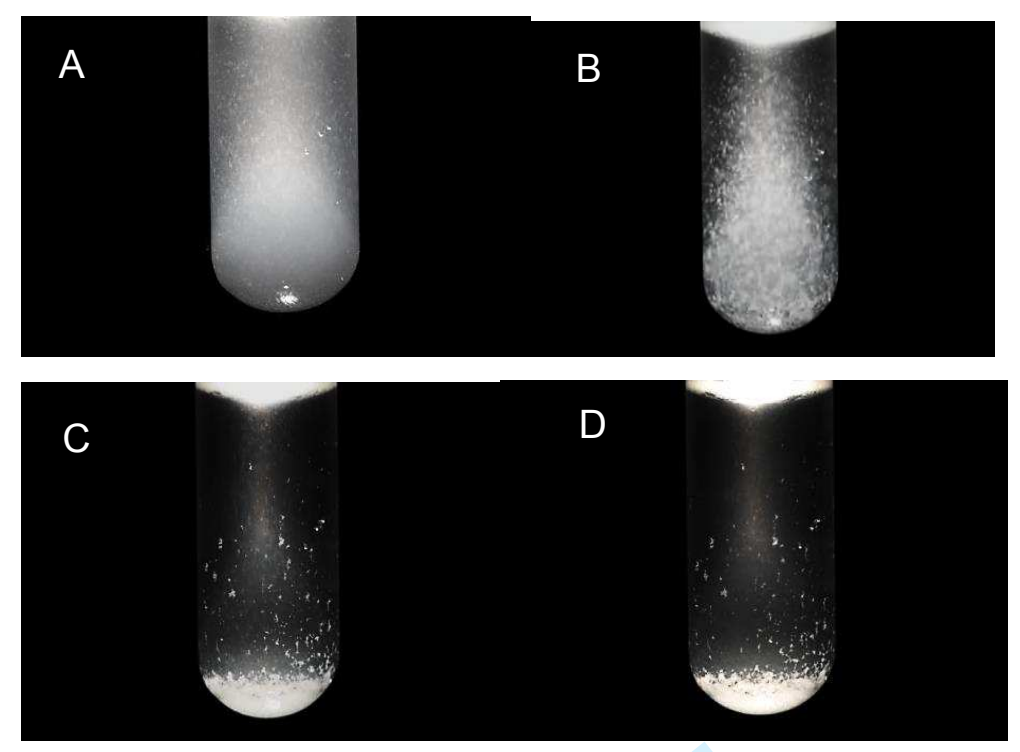


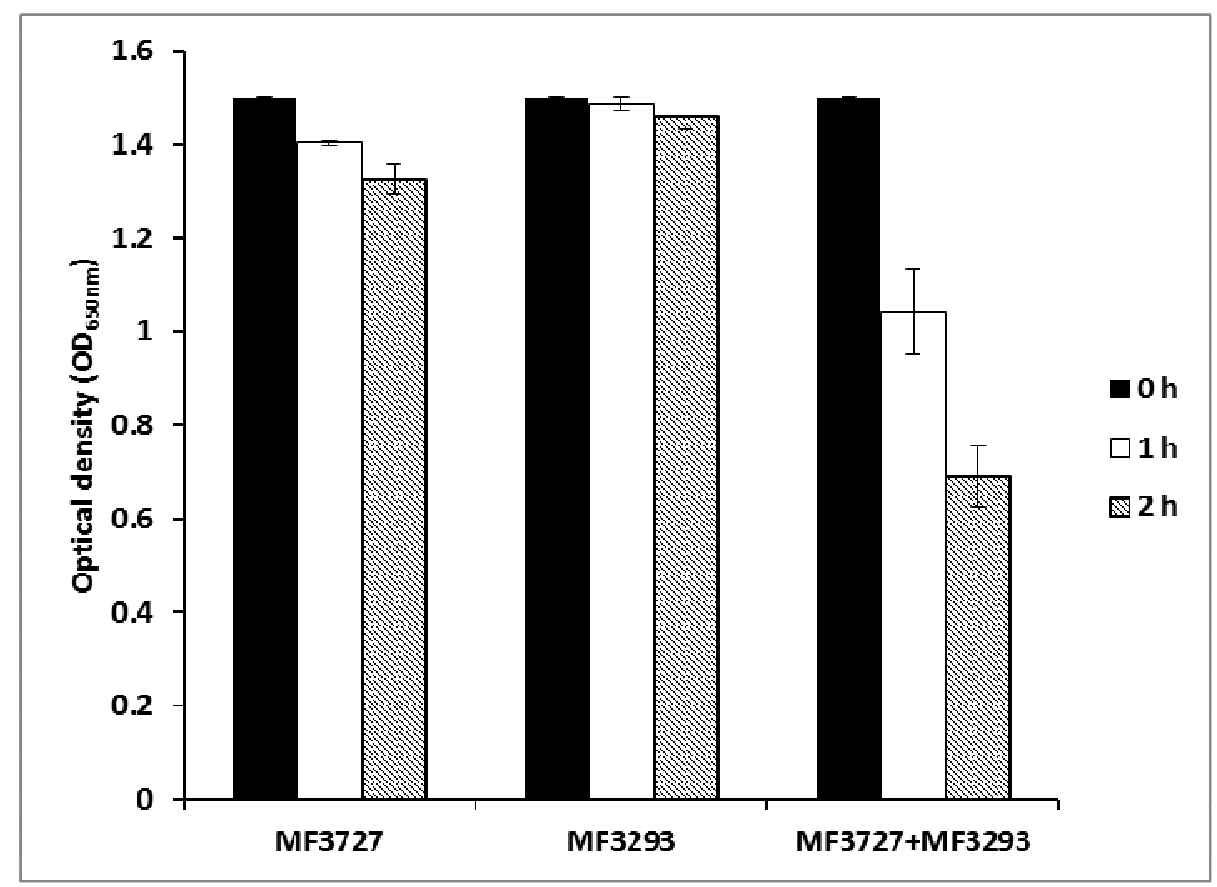



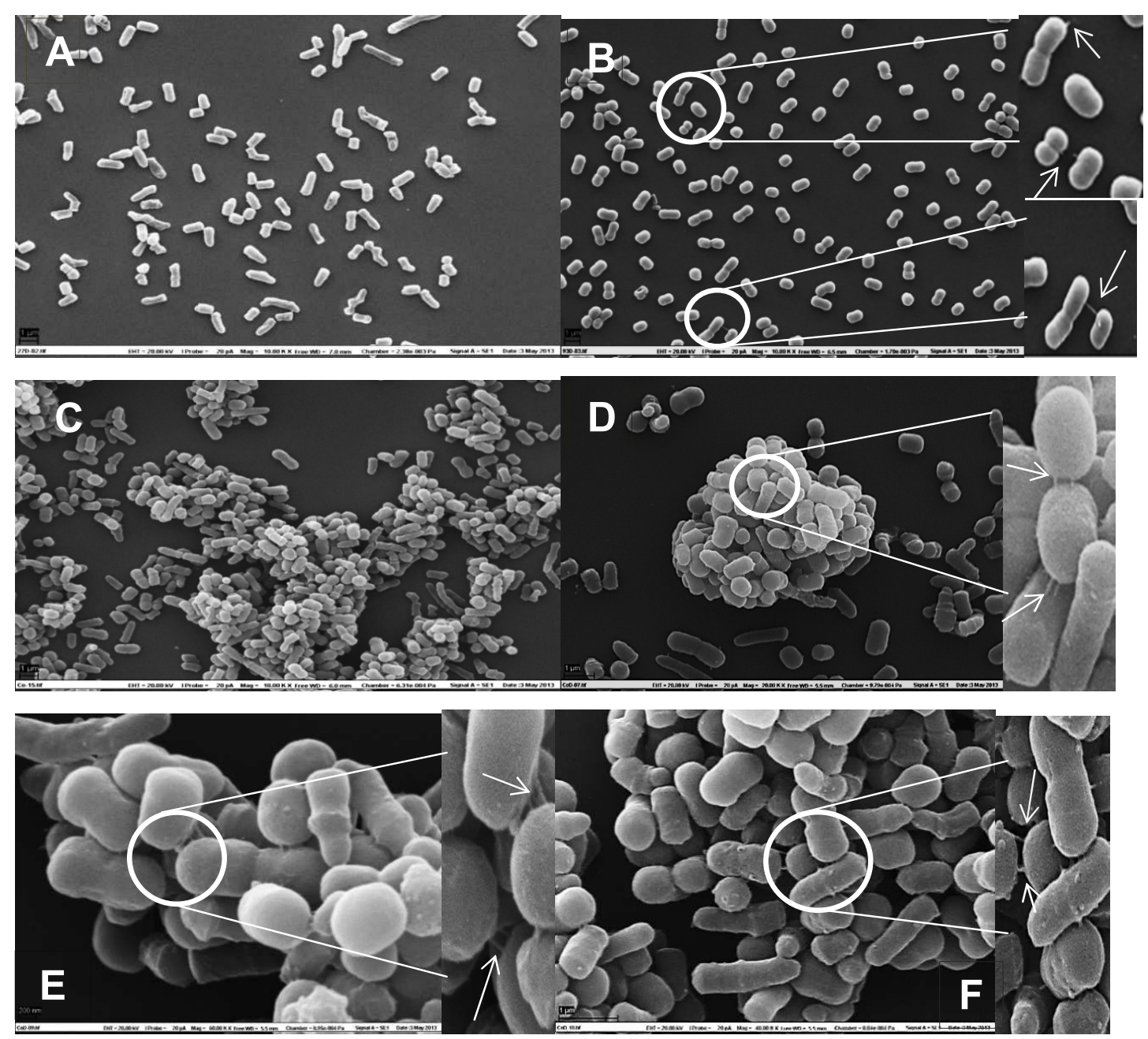
Fig 4a

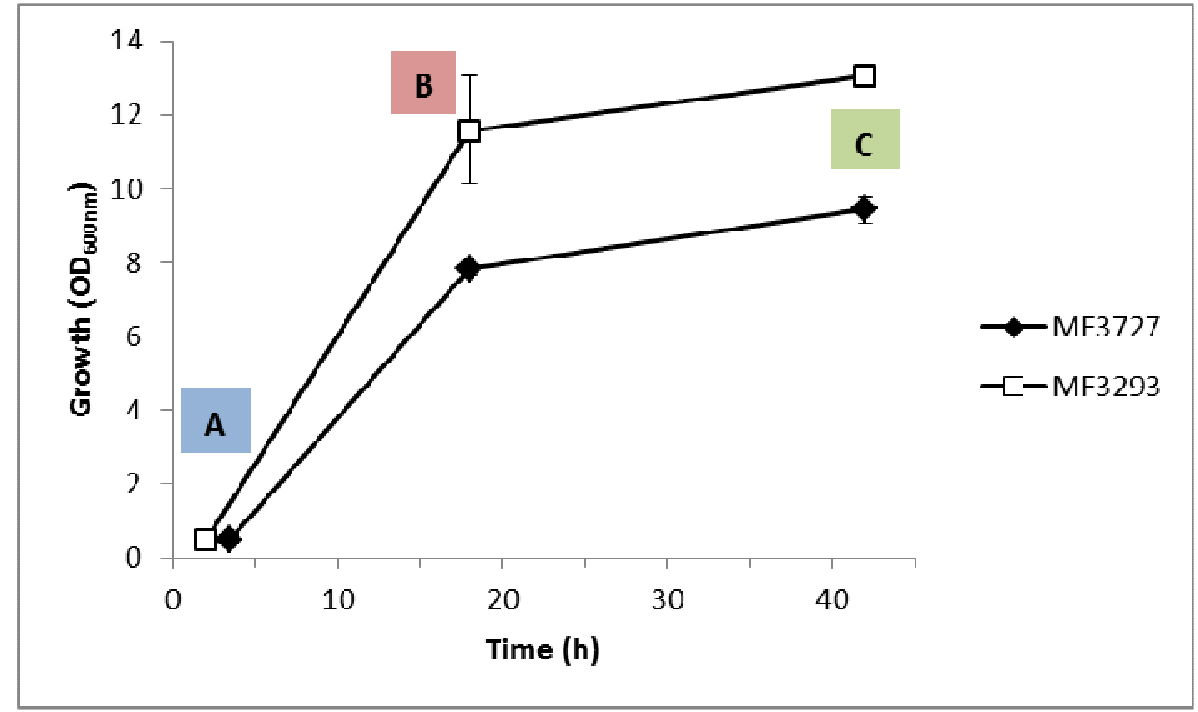

Fig $4 b$

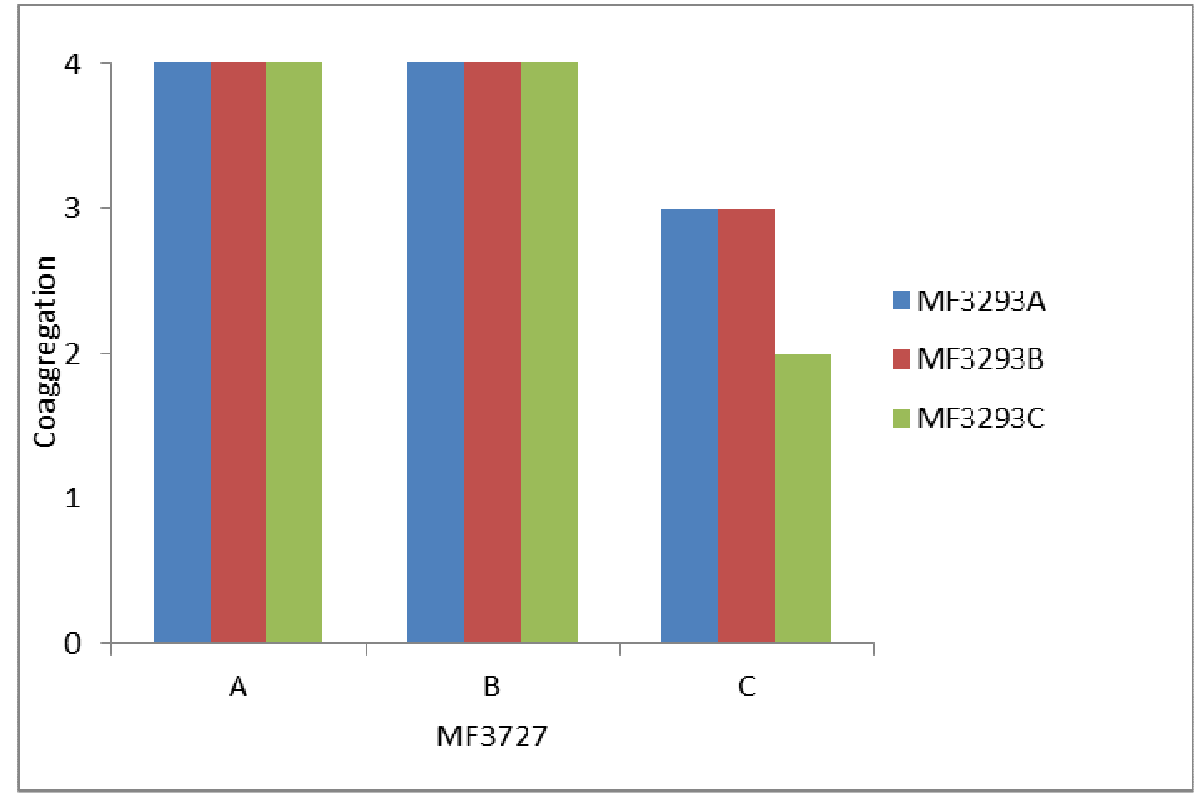




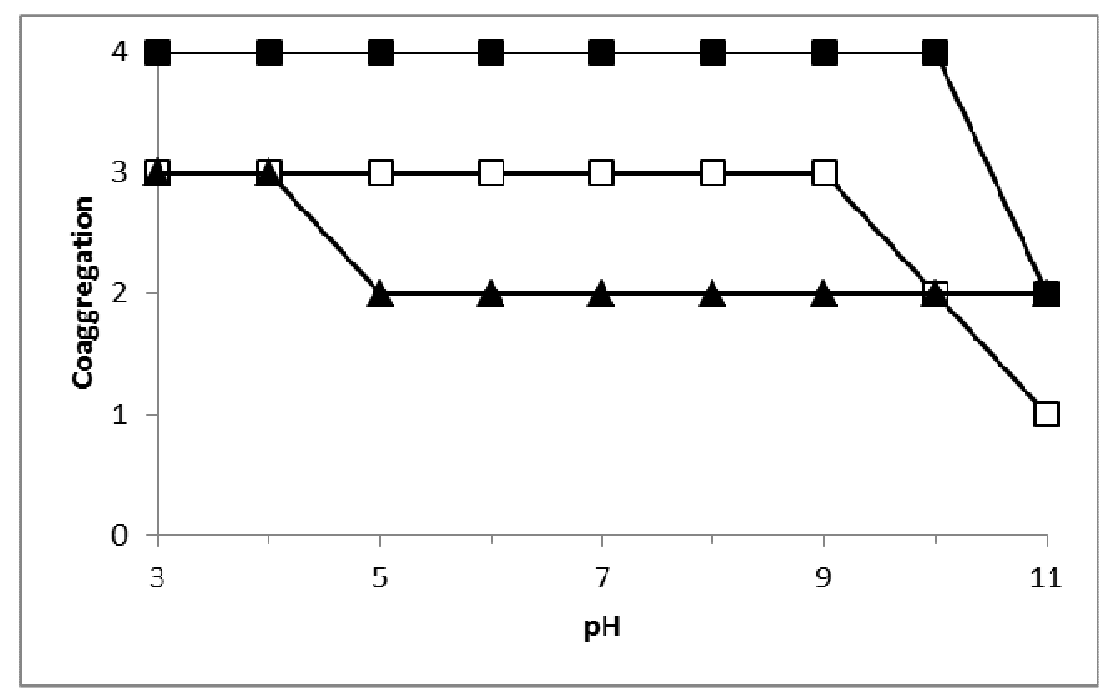




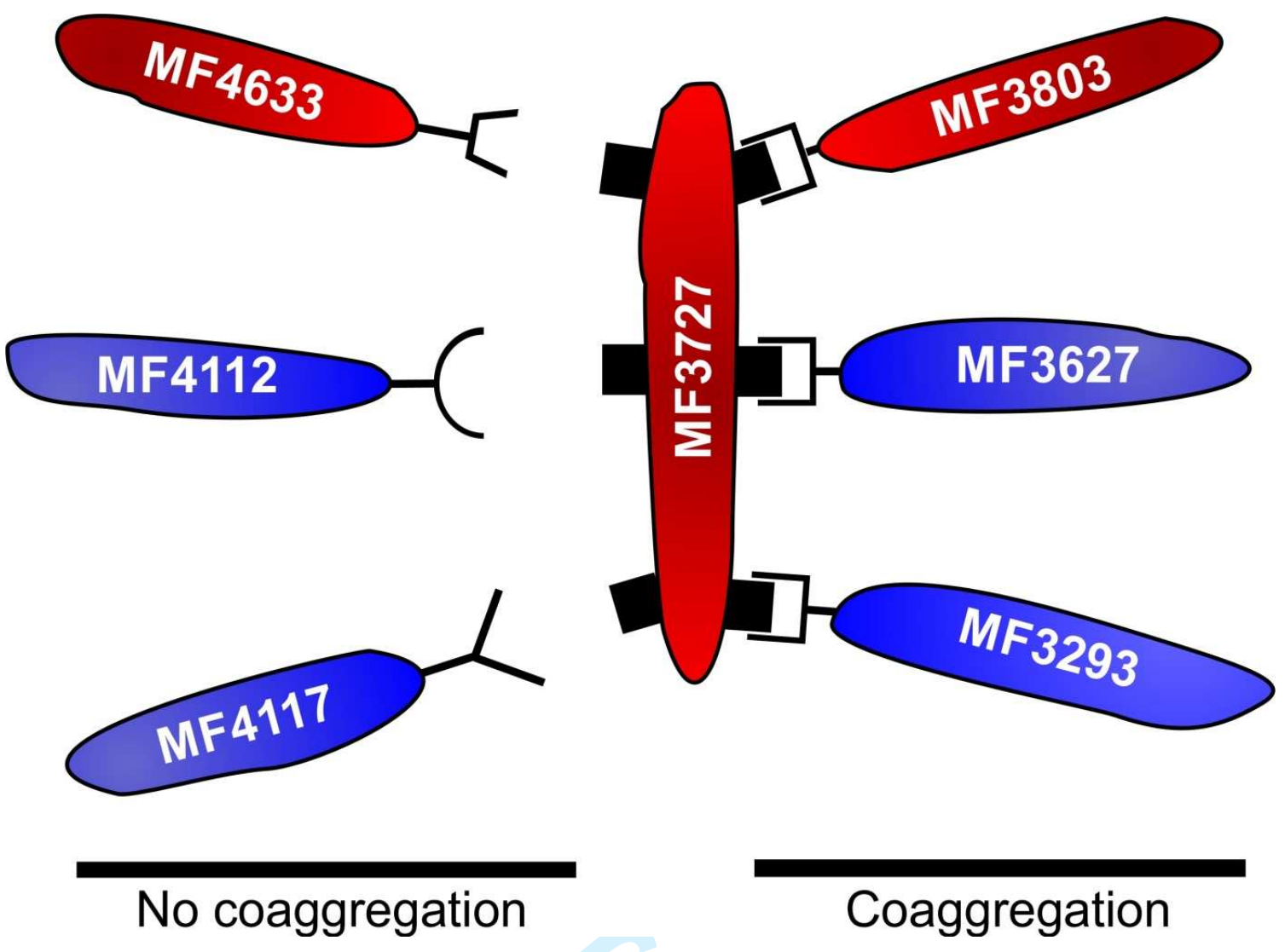

